\title{
Guest editorial: B1 cells: their ontogeny and malignant counterpart
}

\author{
Naoyuki Katayama ${ }^{1}$
}

Received: 26 March 2020 / Accepted: 27 March 2020 / Published online: 8 April 2020

(c) Japanese Society of Hematology 2020

All multicellular organisms have the strategies to defend themselves against invading pathogens. One of the body's defense mechanisms is the immune system which mainly consists of innate and adaptive immunities. Innate immune responses as a first-line of defense are initiated immediately after exposure to pathogens. Because these immune responses are general defense reactions, they do not depend on previous exposure to the pathogens. A group of proteins and phagocytes such as macrophages and neutrophils recognize the pathogen-specific molecules and disrupt the pathogens. The innate immune system can recruit the effective adaptive immune responses. Adaptive immune responses as a more sophisticated defense are mounted by the specific $\mathrm{T}$ cells and $\mathrm{B}$ cells that can respond to various pathogens including viruses, bacteria, fungi, parasites, infected host cells, and tumor cells. Basically, the adaptive immune responses are not directed against self molecules, but against foreign ones. When the regulatory mechanisms fail to work, the adaptive immune system turns against the host and cause autoimmune diseases.

$\mathrm{T}$ cells induce $\mathrm{T}$ cell mediated immune responses, while $\mathrm{B}$ cells elicit antibody responses. The elaborate studies of $\mathrm{T}$ cell mediated responses facilitated the discovery of a new subset of $\mathrm{CD}^{+}{ }^{+} \mathrm{T}$ cells, forkhead box protein P3 (FOXP3) ${ }^{+}$regulatory $\mathrm{T}(\mathrm{Treg})$ cells which play a critical role in immune hemostasis and regulation. Although Treg cells are a small population in $\mathrm{CD} 4^{+} \mathrm{T}$ cells, they exhibit highly suppressive activities on effector $\mathrm{T}$ cells including $\mathrm{CD} 4^{+}$ helper $\mathrm{T}$ cells and $\mathrm{CD} 8^{+}$cytotoxic $\mathrm{T}$ cells. These findings demonstrate the great importance of a small population of lymphocytes in immune regulation.

Naoyuki Katayama

n-kata@clin.medic.mie-u.ac.jp

1 Department of Hematology and Oncology, Mie University Graduate School of Medicine, 2-174 Edobashi, Tsu, Mie 514-8507, Japan
B cells are composed of two populations, B1 cells and B2 cells. B2 cells are a major population of B cells and their two main components are naïve and memory B cells. During postnatal hematopoiesis, B2 cells originate from hematopoietic stem cells (HSCs) in the bone marrow. In the development of B2 cells, the heavy-chain locus of immunoglobulin (Ig) gene is successfully rearranged followed by the production of a $\mu$ heavy chain in the cytoplasm which is the pre-B cell receptor. If the subsequent light-chain rearrangement is productive, a B-cell receptor (IgM) is expressed on the surface of an immature B cell. Immature B cells emerge to the periphery when the cells express $\operatorname{IgD}$ as well as $\operatorname{IgM}$ and differentiate into mature $B$ cells. A mature B cell is activated when it encounters and binds a specific antigen which is recognized by IgM on its cell surface. Activated B cells emigrate to the secondary lymphoid tissues and receive T-cell help. Some of activated B cells differentiate into antibodyproducing cells which synthesize the first antibody IgM specific for the respective antigens. Consequently, class switch recombination occurs and then activated proliferating B cells differentiate into long-lived plasma cells and migrate to the bone marrow where they produce $\operatorname{IgG}, \operatorname{Ig} A$, $\operatorname{IgD}$, or $\operatorname{IgE}$ antibodies.

In the case of $\mathrm{B}$ cells, considerable attentions have been attracted to a small population of B cells, B1 cells, which are likely to have a pivotal function in the immune system. A p69,71 complex (Leu-1) and Ly-1, both referred to as CD5, one of T cell surface molecules, had been reported to be expressed on human chronic lymphocytic leukemia (CLL) cells and murine B cell lymphoma cells, respectively $[1,2]$. Murine normal B1 cells were identified by Hayakawa et al. as a small subset of splenic B cells carrying Ly-1 [3]. B1 cells display different development, tissue distribution, and functions from B2 cells [4]. It has been thought that the majority of B1 cells are generated from B1 cell restricted progenitors in the fetal liver and are mainly maintained by their self-renewal activity, at least in the murine system. B1 cells are present at a low frequency in the secondary 
lymphoid organs, but abundant in the peritoneal and pleural cavities. A key feature of B1 cells is to be involved in the innate immunity. They can spontaneously secrete natural antibodies, the $\operatorname{IgM}$, in the absence of T cell-help, prior to exogenous antigen stimulation. These antibodies also respond to self-antigens. An increasing amount of evidence regarding B1 cells and their malignant counterpart has been accumulated.

In 1993, I got to know the existence of B1 cells for the first time when I was talking with Dr. Toshiyuki Ohno, one of my colleagues in our department in those days, who reported $\mathrm{CD}^{+}$diffuse large cell lymphoma [5] and then I decided to study the ontogeny of human adult B1 cells someday. I had kept this project in mind for approximately 20 years until our laboratory could satisfy the requirements for the implementation of this project. As our study design was approved by the Independent Ethics Committee for Human Research at Mie University Graduate School of Medicine on February 1,2016, we started the project on the ontogeny of human B1 cells. Coincidentally, on the same day, Quách et al. published the paper in Journal of Immunology in which they identified the definitive phenotype of human B1 cells [6]. On the basis of their proposal of the phenotype of human B1 cells, we examined the ontogeny of human adult B1 cells in adults, that is to say, whether human adult HSCs in the bone marrow can produce B1 cells and submitted our data for publication. The elegant study by Sawai et al. demonstrated that murine HSCs can give rise to a limited but definite number of B1 cells [7]. On May 10, 2019, the Editor-in-Chief of International Journal of Hematology, Professor Takaori, asked me to organize the "Progress in Hematology" session in the future issue. Eight days later, I received the e-mail saying that our paper was accepted for publication, in the car on the way home from the 10th JSH International Symposium 2019 in Ise-Shima. The theme entitled "B1 cells: their ontogeny and malignant counterpart" instantly came to my mind. This is the reason why the "Progress in Hematology" session in this issue has focused on the origin of B1 cells and their malignant counterpart.

Dr. Momoko Yoshimoto and her colleagues from Center for University of Texas Health Science at Houston have actively investigated the development of murine B-1 a cells. The origin and development of murine B1 cells have been investigated in more detail than those of human B1 cells, because the collection and use of fetal tissues are limited in humans. Her article reviews the origin of murine B-1 cells in the adult bone marrow and fetal liver, and then discusses multiple waves of B-1 lymphopoiesis.

Proximal nocturnal hemoglobinuria (PNH) and chronic myeloid leukemia (CML) are clonal HSC disorders in which a part of B cells is derived from HSCs harboring PIGA gene mutations and the $B C R-A B L 1$ fusion gene, respectively. The observation, by Yuki Kageyama and me from Mie University, that a small population of B1 cells in peripheral blood have PIGA gene mutations or the $B C R-A B L 1$ fusion gene proposes the potential of human adult HSCs to produce B1 cells.

Dr. Yoshikane Kikushige from Kyushu University comprehensively reviews current information concerning the genetic events detected in CLL cells and also refers to the possibility that CLL cells are the malignant counterpart of human B1 cells. He is the first author of the outstanding paper that provides a new conceptual understanding of the pathophysiology of CLL. He and his colleagues found that HSCs from patients with CLL acquired the genetic alternations that define monoclonal or oligoclonal B cell differentiation.

The extensive studies have elucidated the cellular characteristics and underlying oncogenic mechanisms of CLL and have contributed to the development of new drugs targeting CLL. Dr. Junji Suzumiya from Shimane University Hospital and Dr. Jun Takizawa from Niigata University are expert physicians in the field of treatment of lymphoid malignancies in Japan. In their article, they go over the literature and provide an overview of current therapeutic strategies for the treatment of CLL, and, furthermore, highlight new drugs for CLL that are in preclinical or clinical development.

I believe that B1 cells are a minor, but important subpopulation of B cells. The results from many studies of physiologic, cytologic, biochemical, and genetic aspects of normal blood cells have contributed to the understanding of underlying mechanisms of various diseases including hematopoietic malignancies and to the development of new therapeutic strategies. Also, various studies on the characteristic properties of malignant blood cells have been useful for the elucidation of development, differentiation, phenotype, and function of normal blood cells. Finally, I really hope that this "Progress in Hematology" session will facilitate further studies of B1 cells and their malignant counterpart, leading to the control of malignant hematopoietic diseases and immunological disorders.

\section{Compliance with ethical standards}

Conflict of interest The author reports personal fees from Celgene and Chugai Pharmaceutical, and grants from Astellas Pharma, Kyowa Kirin, Ono Pharmaceutical, and Takeda Pharmaceutical, outside the submitted work.

\section{References}

1. Wang CY, Good RA, Ammirati P, Dymbort G, Evans RL. Identification of a p69,71 complex expressed on human $T$ cells sharing 
determinants with B-type chronic lymphatic leukemic cells. J Exp Med. 1980;151:1539-44.

2. Lanier LL, Warner NL, Ledbetter JA, Herzenberg LA. Expression of Lyt-1 antigen on certain murine B cell lymphomas. J Exp Med. 1981;153:998-1003.

3. Hayakawa K, Hardy RR, Parks DR, Herzenberg LA. The "Ly-1 B" cell subpopulation in normal immunodefective, and autoimmune mice. J Exp Med. 1983;157:202-18.

4. Prieto JMB, Felippe MJB. Development, phenotype, and function of non-conventional B cells. Comp Immunol Microbiol Infect Dis. 2017;54:38-44.

5. Ohno T, Yamaguchi M, Oka K, Tsukada T, Kita K, Kobayashi T, Shorakawa S. CD5 expression and its significance in B-cell lymphomas. J Clin Exp Hematopathol. 1993;33:31-44 (In Japanese).
6. Quách TD, Rodríguez-Zhurbenko N, Hopkins TJ, Guo X, Hernández AM, Li W, et al. Distinctions among circulating antibodysecreting cell populations, including B-1 cells, in human adult peripheral blood. J Immunol. 2016;196:1060-9.

7. Sawai CM, Babovic S, Upadhaya S, Knapp D, Lavin Y, Lau CM, et al. Hematopoietic stem cells are the major source of multilineage hematopoiesis in dult animals. Immunity. 2016;45:597-609.

Publisher's Note Springer Nature remains neutral with regard to jurisdictional claims in published maps and institutional affiliations. 